\title{
Climate policy under sustainable discounted utilitarianism*
}

\author{
Simon Dietz ${ }^{\dagger} \quad$ Geir B. Asheim ${ }^{\ddagger}$
}

January 13, 2012

\begin{abstract}
Empirical evaluation of policies to mitigate climate change has been largely confined to the application of discounted utilitarianism (DU). DU is controversial, both due to the conditions through which it is justified and due to its consequences for climate policies, where the discounting of future utility gains from present abatement efforts makes it harder for such measures to justify their present costs. In this paper, we propose sustainable discounted utilitarianism (SDU) as an alternative principle for evaluation of climate policy. Unlike undiscounted utilitarianism, which always assigns zero relative weight to present utility, SDU is an axiomatically based criterion, which departs from DU by assigning zero weight to present utility if and only if the present is better off than the future. Using the DICE integrated assessment model to run risk analysis, we show that it is possible for the future to be worse off than the present along a 'business as usual' development path. Consequently SDU and DU differ, and willingness to pay for emissions reductions is (sometimes significantly) higher under SDU than under DU. Under SDU, stringent schedules of emissions reductions increase social welfare, even for a relatively high utility discount rate.

Keywords: Climate change; discounted utilitarianism; intergenerational equity; sustainable development; sustainable discounted utilitarianism
\end{abstract}

JEL Classification Numbers: D63, D71, Q01, Q54

*Dietz's research has been supported by the Grantham Foundation for the Protection of the Environment, as well as the Centre for Climate Change Economics and Policy, which is funded by the UK's Economic and Social Research Council (ESRC) and by Munich Re. Asheim's research is part of the activities at the Centre for the Study of Equality, Social Organization, and Performance (ESOP) at the Department of Economics, University of Oslo. ESOP is funded by the Research Council of Norway. Asheim's research has also been supported by l'Institut d'études avancées - Paris. We thank Marc Fleurbaey, Cameron Hepburn, an editor, two anonymous referees and participants at the Ulvön and EAERE conferences for helpful comments. The usual disclaimers apply.

${ }^{\dagger}$ Grantham Research Institute on Climate Change and the Environment, and Department of Geography and Environment, London School of Economics and Political Science (LSE), Houghton Street, London WC2A 2AE, UK (tel: +44 (0) 2079557589 fax: +44 (0) 2071075441 e-mail: s.dietz@lse.ac.uk).

${ }^{\ddagger}$ Dept. of Economics, University of Oslo, P.O. Box 1095 Blindern, 0317 Oslo, Norway (tel: +47 22855498 fax: +4722855035 e-mail: g.b.asheim@econ.uio.no). 


\section{Introduction}

Empirical evaluation of policies to mitigate climate change has been largely confined to the application of discounted utilitarianism (DU). DU means that one stream of consumption is deemed better than another if and only if it generates a higher sum of utilities discounted by a constant and positive per period utility discount rate $\rho$.

In spite of its prevalence, DU is controversial, both due to the conditions through which it is justified and due to its consequences for choice in economically relevant situations, such as climate-change policy. As a matter of principle, DU gives less weight to the utility of future generations and therefore treats generations in an unequal manner. If one abstracts from the probability that the world will be coming to an end, thereby assuming that any generation will appear with certainty, it is natural to question whether it is fair to value the utility of future generations less than that of the present one. This criticism has a long tradition dating back at least as far as Ramsey (1928, p. 543), who argued that the practice of discounting later enjoyments in comparison with earlier ones "is ethically indefensible and arises merely from the weakness of the imagination".

When applied to evaluating climate policies, DU means that the future utility gains of present abatement efforts are discounted, which makes it harder for such measures to justify their present costs. This was one of the earliest findings in the economic literature on climate change (cf. Cline, 1992; Nordhaus, 1991).

One way of treating generations equally is to evaluate policies according to undiscounted utilitarianism, whereby the utility discount rate is set to zero so that future utilities are summed without being discounted. This alternative was highlighted during the debate following the publication of the Stern Review (2007), which, while committed to DU, applied a utility discount rate of very nearly zero. However, such a criterion (or DU with a near-zero utility discount rate) may contradict our ethical intuitions if used to evaluate all investments, as it is prone to impose heavy sacrifices on the present generation for the benefit of future generations that are likely to be much better off (Arrow, 1999; Dasgupta, 2007; Mirrlees, 1967; Rawls, 1971). The reason for this weakness of undiscounted utilitarianism is that it assigns zero relative weight to present utility under all circumstances, i.e. even when the present is worse off than the future.

Sustainable discounted utilitarianism (SDU), proposed by Asheim and Mitra (2010), avoids the pitfalls of DU (which is too willing to sacrifice future genera- 
tions) and undiscounted utilitarianism (which is too willing to sacrifice the present generation).

SDU departs from DU by placing the additional constraint on social welfare evaluation that the utility discount rate is set to zero if present utility exceeds future welfare. $^{1}$ Hence, in this case - and only in this case - is zero relative weight assigned to present utility. For example, if the future consequences of climate change entail that present utility exceeds future welfare, then SDU takes into account the future welfare benefits of present mitigation efforts, while ignoring their current costs. Therefore, if there is a non-negligible probability that climate change will undermine future wellbeing, then SDU promotes present action more than DU. However, SDU coincides with DU with a positive utility discount rate if the future will for sure be better off than the present in spite of climate change.

If the future will be better off than the present, then additional present sacrifice for the benefit of the future may increase the undiscounted sum of present and future utilities. It also increases the verge between present and future wellbeing, thus making the intergenerational distribution more unequal. Therefore, it seems uncontroversial to allow a trade-off between present and future wellbeing in such circumstances. However, if the future will be worse off than the present, then additional present sacrifice leading to a uniform increase of future wellbeing increases the undiscounted sum of present and future utilities and decreases inequality. Hence, such a transfer from the present to the future is desirable both from a utilitarian and egalitarian perspective. This is the ethical underpinning for a condition called "Hammond Equity for the Future", which gives priority to the future in conflicts where the future is worse off than the present.

"Hammond Equity for the Future" is the key condition in the axiomatic basis for SDU, as investigated by Asheim et al. (2012). SDU also satisfies Chichilnisky's (1996) "No Dictatorship of the Present". In contrast, DU is in conflict both with "Hammond Equity for the Future", as it allows a trade-off between present and future wellbeing even when the present is better off than the future, and "No Dictatorship of the Present", as the ranking of DU (on the set of bounded streams) does not depend on what happens beyond some finite future point in time.

Compared to DU, imposing "Hammond Equity for the Future" comes at the cost

\footnotetext{
${ }^{1}$ This statement presupposes that welfare is normalised in a way that allows for meaningful comparison of utility derived from present consumption with welfare derived from the future consumption stream. In Section 2 we explain how we ensure this.
} 
of (i) removing sensitivity to the interests of the present if the present is better off than the future and (ii) relaxing to the set of non-decreasing streams the property that the trade-off between wellbeing in the first two periods be separable from the remainder of the stream. Regarding (i), there is a large literature, starting with Diamond (1965), which has established a conflict between imposing equity conditions (like equal treatment and "Hammond Equity for the Future") on the one hand, and remaining sensitive to the interests of every generation on the other. Asheim et al. (2012, Section 4) present a formal analysis showing how imposing on the set of all streams the separability property of DU mentioned under (ii) is in conflict with equity conditions that respect the interests of future generations.

The present paper proposes SDU as an alternative criterion to DU for the evaluation of climate abatement policies, and it seeks to illustrate that substituting SDU for DU matters for empirical evaluation of such policies. We do so by considering the DICE integrated assessment model, built by William Nordhaus, but where we run risk analysis, including alternative specifications for the important parameters determining the climate sensitivity and damage function. Weitzman (2009, 2010a,b) in particular has raised doubt concerning the climate sensitivity and damage function used in the standard DICE model. Our alternative specifications lead to a non-negligible probability that some generation is better off than its descendants, in which case adopting SDU instead of DU matters for the evaluation, so much so that we are able to show aggressive emissions abatement increases social welfare under SDU, even when the utility discount rate is relatively high. By contrast, we confirm that such abatement policies fail to increase social welfare under DU. We also show that the optimal abatement policy is more stringent under SDU than DU.

Our analysis is ethical in nature, asking what our generation as a collective should do to serve the interests of all generations from an impartial perspective. This is different from taking a strategic perspective, asking what contemporary countries or individuals should do to serve their own interests when such actions influence the future strategic actions of other countries and individuals. Nevertheless, since SDU bridges the gap between DU and undiscounted utilitarianism, we believe it is realistic to suggest that its recommendations are of interest for current decision-makers.

The paper is organised as follows. In Section 2 we present formally the concept of SDU. While Asheim and Mitra (2010) have already done so in a deterministic setting and without explicit consideration of population growth, empirical evaluation of climate policies does not permit either of these simplifications, so Section 2 extends 
SDU to variable population and uncertainty. In Section 3 we present risk analysis with DICE, discussing in particular our choice of climate sensitivity and damage function, before in Section 4 reporting the results from our analysis. As we discuss in the concluding Section 5, the present paper should be considered a first effort in combining recent advances in axiomatic theories of intertemporal social choice (for a survey, see Asheim, 2010) with empirical evaluation of climate-change policies. Nevertheless, we claim that our analysis is strongly indicative of the importance of broadening the basis of climate-policy evaluation from DU to SDU and beyond.

\section{What is Sustainable Discounted Utilitarianism?}

In the empirical part of this paper we consider only consumption streams which eventually become constant. ${ }^{2}$ This setting simplifies the presentation of SDU, and we refer the reader to Asheim and Mitra (2010) for the more general treatment.

Let $c_{t}>0$ denote consumption in period $t$, and let ${ }_{t} \mathbf{c}=\left(c_{t}, \ldots, c_{\tau}, \ldots\right)$ be an infinite stream of consumption, where there exists $T \geq t$ such that $c_{\tau}=c_{T}$ for all $\tau \geq T$. A consumption stream ${ }_{t} \mathbf{c}$ is called egalitarian if $c_{\tau}=c_{t}$ for all $\tau \geq t$.

Utility in a period is derived from consumption in that period alone. The utility function $U$ is assumed to be strictly increasing, strictly concave, continuous and continuously differentiable for $c>0$ with $U^{\prime}(c) \rightarrow \infty$ as $c \rightarrow 0$. Clearly, any utility function with constant relative inequality aversion satisfies these assumptions.

Let $\rho>0$ denote the utility discount rate to be used under DU, and under SDU provided present utility does not exceed future welfare. Let $\delta \in(0,1)$ denote the corresponding utility discount factor. The relation between $\rho$ and $\delta$ is given by

$$
\delta=\frac{1}{1+\rho}
$$

Note that setting the utility discount rate to 0 corresponds to setting the utility discount factor to 1 ; doing so leads to zero relative weight on present utility. The theoretical presentation of SDU in this section is facilitated by using the utility discount factor $\delta$, while the numerical results in Section 4 are easier to interpret in terms of the utility discount rate $\rho$. Keeping in mind eq. (1) (and eq. (3) in the case of variable population analysed in subsection 2.1 ), this should not create confusion.

\footnotetext{
${ }^{2}$ We use a modelling horizon from 2005 to 2395 and assume that consumption remains at the 2395 level thereafter.
} 
In the axiomatic analysis of Asheim and Mitra (2010), time periods correspond to non-overlapping generations assumed to follow each other in sequence. In the empirical analysis of this paper, time periods are shorter, set to ten years (given by the time-step of the DICE model). As long as the discount factor is properly adjusted to reflect a plausible trade-off between present utility and future welfare, this choice of period length does not matter.

With overlapping generations, discounting from an ethical perspective between different generations should be differentiated from the self-interested discounting that people do within their own lifetimes, and our analysis - following most literature on climate-policy evaluation - does not reflect the need to do such differentiation.

Given any $\delta \in(0,1)$, the social welfare function (SWF) $w$ defined by

$$
w\left({ }_{t} \mathbf{c}\right)=(1-\delta) \sum_{\tau=t}^{\infty} \delta^{\tau-t} U\left(c_{\tau}\right)
$$

is the discounted utilitarian (DU) SWF. Multiplying by $1-\delta$ ensures that the utility weights $\left(1-\delta,(1-\delta) \delta,(1-\delta) \delta^{2}, \ldots\right)$ add up to one. Such a normalisation is essential for the analysis of this paper, as it makes the utility of each generation comparable to the welfare of the stream.

The DU SWF is well-defined for the set of consumption streams which eventually become constant. Furthermore, on this set, it is characterized by

$$
\begin{aligned}
& \left.w{ }_{t} \mathbf{c}\right)=(1-\delta) U\left(c_{t}\right)+\delta w\left({ }_{t+1} \mathbf{c}\right) \\
& \left.w{ }_{t} \mathbf{c}\right)=U\left(c_{t}\right) \quad \text { if }{ }_{t} \mathbf{c} \text { is egalitarian. }
\end{aligned}
$$

Clearly, (2) implies (w.1) and (w.2). Conversely, for any ${ }_{0} \mathbf{c}=\left(c_{0}, \ldots, c_{\tau}, \ldots\right)$ with $c_{\tau}=c_{T}$ for all $\tau \geq T$, it follows from (w.2) that

$$
w\left({ }_{T} \mathbf{c}\right)=U\left(c_{T}\right)=(1-\delta) \sum_{\tau=T}^{\infty} \delta^{\tau-T} U\left(c_{\tau}\right)
$$

Repeated use of (w.1) for $t=T-1, T-2, \ldots, 1,0$, now yields (2) for $t=0$.

The sustainable discounted utilitarian (SDU) SWF modifies DU by requiring that an SDU SWF not be sensitive to the interests of the present generation if the present is better off than the future:

$$
\begin{aligned}
& W\left({ }_{t} \mathbf{c}\right)= \begin{cases}(1-\delta) U\left(c_{t}\right)+\delta W\left({ }_{t+1} \mathbf{c}\right) & \text { if } U\left(c_{t}\right) \leq W\left({ }_{t+1} \mathbf{c}\right) \\
W\left({ }_{t+1} \mathbf{c}\right) & \text { if } U\left(c_{t}\right)>W\left({ }_{t+1} \mathbf{c}\right)\end{cases} \\
& W\left({ }_{t} \mathbf{c}\right)=U\left(c_{t}\right) \quad \text { if }{ }_{t} \mathbf{c} \text { is egalitarian }
\end{aligned}
$$


Condition (W.1) means that future utilities are not discounted (the discount factor is set to 1 ; the utility discount rate is set to 0 ) if the present is better off than the future. In this case, present utility is given zero weight. The utility weights are still of the form $\left(1-\delta,(1-\delta) \delta,(1-\delta) \delta^{2}, \ldots\right)$ if generations with zero utility weight are left out, implying that the utility weights add up to one also for the SDU SWF. This means that the utility of each generation is comparable to the welfare of the stream and makes the comparison between $U\left(c_{t}\right)$ and $W\left({ }_{t+1} \mathbf{c}\right)$ meaningful and independent of the period length. In particular, the welfare of an egalitarian stream is equal to the utility of the constant level of consumption, as specified by condition (W.2).

For any $0 \mathbf{c}=\left(c_{0}, \ldots, c_{\tau}, \ldots\right)$ with $c_{\tau}=c_{T}$ for all $\tau \geq T$, it follows from (W.2) that $W\left({ }_{T} \mathbf{c}\right)=U\left(c_{T}\right)$. Repeated use of (W.1) for $t=T-1, T-2, \ldots, 1,0$, now allows us to recursively calculate $W\left(T_{-1} \mathbf{c}\right), W\left(T_{-2} \mathbf{c}\right)$, and so on, ending up with $W\left({ }_{0} \mathbf{c}\right)$. Hence, on our domain of eventually constant consumption streams, the SDU SWF is uniquely determined.

For given utility discount factor $\delta$, the concavity of the $U$-function and $W\left({ }_{t} \mathbf{c}\right)$ being the minimum of $(1-\delta) U\left(c_{t}\right)+\delta W\left({ }_{t+1} \mathbf{c}\right)$ and $W\left(_{t+1} \mathbf{c}\right)(\mathrm{cf}$. (W.1)) both express a preference for consumption smoothing over time. The Ramsey model of optimal growth can be used to show that these instruments are not redundant (see Asheim and Mitra, 2010, Section 4). If initial capital productivity is higher than the one corresponding to the modified Golden Rule, then the SDU-optimal stream coincides with the increasing DU-optimal stream and the concavity of the $U$-function smooths consumption as for the DU-optimal stream. However, if initial capital productivity is lower than the one corresponding to the modified Golden Rule, then (W.1) implies that the SDU-optimal stream coincides with the efficient egalitarian stream. For such initial conditions, DU leads to a decreasing optimal stream for any choice of strictly increasing and strictly concave $U$-function, thereby representing preferences in conflict with the condition of "Hammond Equity for the Future".

The following proposition establishes as a general result that SDU welfare coincides with DU welfare on the set of non-decreasing streams. Also, it shows that SDU welfare is a non-decreasing function of time and bounded above by DU welfare.

Proposition 1 Assume that ${ }_{0} \mathbf{c}$ is eventually constant.

(i) For all $t \geq 0, W\left({ }_{0} \mathbf{c}\right) \leq W\left({ }_{t} \mathbf{c}\right) \leq w\left({ }_{t} \mathbf{c}\right)$

(ii) If ${ }_{0} \mathbf{c}$ is non-decreasing, then $W\left({ }_{0} \mathbf{c}\right)=w\left({ }_{0} \mathbf{c}\right)$. 
Proof. This is a special case of Asheim and Mitra (2010, Proposition 2).

Part (ii) means that SDU welfare differs from DU welfare only if the consumption stream is not non-decreasing. Hence, existence of some $t \geq 0$ such that $c_{t}>c_{t+1}$ is a necessary, but insufficient, condition for SDU welfare being strictly below DU welfare, and emphasis will be placed on this possibility in the empirical analysis.

On the set of non-increasing streams, SDU coincides with both maximin and numerically representable criteria that depend only on the streams' limiting properties. While such criteria satisfy the condition of "Hammond Equity for the Future" by giving priority to the future in conflicts where the future is worse off than the present, they are extremely insensitive of the interests of generations and yield very different conclusions from SDU for streams that are not non-increasing. In particular, maximin assigns no weight to any generation but the worst off, while criteria that depend on the limiting properties assign no weight to any finite subset of generations.

The stationary equivalent consumption $\bar{c}$ of a consumption stream ${ }_{0} \mathbf{c}$ is the consumption level $\bar{c}$, which if held constant yields the same welfare as the consumption stream ${ }_{0} \mathbf{c}$. By (w.2), the stationary equivalent consumption $\bar{c}$ of a consumption stream ${ }_{0} \mathbf{c}$ under DU satisfies $U(\bar{c})=w\left({ }_{0} \mathbf{c}\right)$, or since $U$ is strictly increasing:

$$
\left.\bar{c}=U^{-1}\left(w{ }_{0} \mathbf{c}\right)\right) \text {. }
$$

By (W.2), the stationary equivalent consumption $\bar{c}$ of a consumption stream ${ }_{0} \mathbf{c}$ under SDU satisfies $U(\bar{c})=W\left({ }_{0} \mathbf{c}\right)$, or since $U$ is strictly increasing:

$$
\left.\bar{c}=U^{-1}\left(W{ }_{0} \mathbf{c}\right)\right) .
$$

We use the stationary equivalent consumption to express non-marginal welfare differences in consumption terms (more on this in Section 4).

Asheim and Mitra (2010) introduce SDU in a deterministic setting where population growth is not explicitly discussed. Application of SDU to climate change, and indeed to a number of other policy issues, requires explicit treatment of population growth and uncertainty, however, and we turn to these issues now.

\subsection{Variable population}

In Asheim and Mitra (2010, p. 150), consumption in period $t$ is interpreted as "a nonnegative indicator of the wellbeing of generation $t$ ". However, how do we compare the wellbeing of the present generation with the wellbeing of future generations if population size changes over time? 
One possibility is to represent the wellbeing of each generation by the product of population size and the utility derived from per-capita consumption. This is the position of 'classical utilitarianism'. An alternative position is to let the wellbeing of each generation depend only on per-capita consumption; this is called 'average utilitarianism'. There is a substantial literature taking a stance in favour of classical utilitarianism (see, e.g. Meade, 1955; Mirrlees, 1967; Dasgupta, 2001; Blackorby et al., 2005). Moreover, this position is standard in the empirical literature on climatepolicy evaluation. Against this background we apply classical utilitarianism in this paper, while carefully observing the need to make meaningful comparisons of present utility with future welfare when developing SDU within this position.

Let $c_{t}=C_{t} / N_{t}$ be per capita consumption at time $t$, where population $N_{t}$ varies exogenously with time. Classical DU welfare at time $t, w_{t}$, depends on

(i) the stream of per-capita consumption ${ }_{t} \mathbf{c}=\left(c_{t}, \ldots, c_{\tau}, \ldots\right)$,

(ii) the development of population ${ }_{t} \mathbf{N}=\left(N_{t}, \ldots, N_{\tau}, \ldots\right)$, and

(iii) the utility discount factor

$$
\beta=\frac{1}{1+\rho}
$$

(where $\rho>0$ so that $\beta \in(0,1)$ ) used to discount the product of population size and the utility derived from per-capita consumption.

It can be expressed by

$$
w_{t}=\frac{\sum_{\tau=t}^{\infty} \beta^{\tau} N_{\tau} U\left(c_{\tau}\right)}{\sum_{\tau=t}^{\infty} \beta^{\tau} N_{\tau}},
$$

where the normalisation ensures that the weights assigned to utility derived from per-capita consumption add up to one when summed over all present and future individuals. In particular, the DU welfare of an egalitarian stream, with per-capita consumption being $c$ at all times, equals $U(c)$. Hence, DU welfare is made comparable to the utility derived from per-capita consumption when being expressed by (4).

By defining a time-dependent population-adjusted utility discount factor $\delta_{t}$ by

$$
\delta_{t}=\frac{\sum_{\tau=t+1}^{\infty} \beta^{\tau} N_{\tau}}{\sum_{\tau=t}^{\infty} \beta^{\tau} N_{\tau}}=1-\frac{\beta^{t} N_{t}}{\sum_{\tau=t}^{\infty} \beta^{\tau} N_{\tau}}
$$

we get the following recursive formula for classical DU welfare:

$$
w_{t}=\frac{\beta^{t} N_{t} U\left(c_{t}\right)}{\sum_{\tau=t}^{\infty} \beta^{\tau} N_{\tau}}+\frac{\sum_{\tau=t+1}^{\infty} \beta^{\tau} N_{\tau} U\left(c_{\tau}\right)}{\sum_{\tau=t}^{\infty} \beta^{\tau} N_{\tau}}=\left(1-\delta_{t}\right) U\left(c_{t}\right)+\delta_{t} w_{t+1} .
$$


If ${ }_{0} \mathbf{c}=\left(c_{0}, \ldots, c_{\tau}, \ldots\right)$ is an infinite stream of per-capita consumption, where there exists $T \geq 0$ such that $c_{\tau}=c_{T}$ for all $\tau \geq T$, then $w_{T}=U\left(c_{T}\right)$ combined with repeated use of (6) allow us to calculate classical DU welfare at time 0.

Likewise, if ${ }_{0} \mathbf{c}=\left(c_{0}, \ldots, c_{\tau}, \ldots\right)$ is an infinite stream of per-capita consumption, with $c_{\tau}=c_{T}$ for all $\tau \geq T$, then $W_{T}=U\left(c_{T}\right)$ combined with repeated use of

$$
W_{t}= \begin{cases}\left(1-\delta_{t}\right) U\left(c_{t}\right)+\delta_{t} W_{t+1} & \text { if } U\left(c_{t}\right) \leq W_{t+1} \\ W_{t+1} & \text { if } U\left(c_{t}\right)>W_{t+1}\end{cases}
$$

allow us to calculate SDU welfare at time 0 . It is also the case that with the recursive formula (7) for SDU welfare, the weights assigned to utility derived from per-capita consumption add up to one when summed over all present and future individuals. Thus, the normalisation ensures that SDU welfare is comparable to the utility derived from per-capita consumption, making the comparison between $U\left(c_{t}\right)$ and $W_{t+1}$ meaningful.

The explicit algorithm defined by $W_{T}=U\left(c_{T}\right)$ and repeated use of (7), with $\delta_{t}$ determined by (5), is used for calculating SDU welfare in the empirical analysis. It follows from (5) that the population-adjusted utility discount factor $\delta_{t}$

- equals the unadjusted utility discount factor $\beta=\frac{1}{1+\rho}$ if population is constant,

- exceeds $\beta$ if there is positive population growth, and

- varies with time if population growth is not exponential.

\subsection{Uncertainty}

Now we turn to the analysis of uncertainty. To handle uncertainty, one can in principle think of two polar approaches in a situation where there is a probability distribution over consumption streams. ${ }^{3}$ One possibility is to adopt an ex post approach by first valuing each realised consumption stream or realisation and then assigning probability weights to the different realisations. An alternative is to adopt an ex ante approach by first determining a certainty equivalent for each generation and then valuing the stream of certainty equivalents. When applying SDU to uncertainty, the choice between these approaches matters for policy evaluation: in the context of climate change, the possibility of catastrophic consequences is assigned

\footnotetext{
${ }^{3}$ In the empirical part this corresponds to the empirical distribution of 250 or 1000 random draws of a Latin Hypercube sample.
} 
more weight in the ex post approach where the valuation is done first within each realisation.

This point can be shown formally under the simplifying assumption that the utility function $U$ not only expresses aversion to fluctuation, but also aversion to risk. By abstracting from population growth and writing $V(u, w):=\min \{(1-\delta) u+\delta w, w\}$ for the function that aggregates present utility and future welfare, it follows from (W.1) that $W\left({ }_{t} \mathbf{c}\right)=V\left(U\left(c_{t}\right), W\left(_{t+1} \mathbf{c}\right)\right)$. The ex post approach of first valuing each realisation and then assigning probability weights to the different realisations yields

$$
\mathbb{E} W\left({ }_{0} \tilde{\mathbf{c}}\right)=\mathbb{E} V\left(U\left(\tilde{c}_{0}\right), W\left({ }_{1} \tilde{\mathbf{c}}\right)\right)=\mathbb{E} V\left(U\left(\tilde{c}_{0}\right), V\left(U\left(\tilde{c}_{1}\right), W\left({ }_{2} \tilde{\mathbf{c}}\right)\right)\right)=\ldots,
$$

while the ex ante approach of first determining a certainty equivalent for each generation and then valuing the stream of certainty equivalents corresponds, in the case where streams are constant from period $T$ on, to using the algorithm defined by $W_{T}^{a}=$ $\mathbb{E} U\left(\tilde{c}_{T}\right)$ and repeated use of $W_{t}^{a}=V\left(\mathbb{E} U\left(\tilde{c}_{t}\right), W_{t+1}^{a}\right)$ for $t=T-1, T-2, \ldots, 1,0$.

Since $V$ is a concave function of $u$ and $w$, it follows from Jensen's inequality that

$$
\mathbb{E} V\left(U\left(\tilde{c}_{0}\right), W\left({ }_{1} \tilde{\mathbf{c}}\right)\right) \leq V\left(\mathbb{E} U\left(\tilde{c}_{0}\right), \mathbb{E} W\left({ }_{1} \tilde{\mathbf{c}}\right)\right),
$$

with strict inequality if both $U\left(c_{0}\right)<W\left({ }_{1} \mathbf{c}\right)$ and $U\left(c_{0}\right)>W\left({ }_{1} \mathbf{c}\right)$ are assigned positive probability. The left-hand side is welfare $\mathbb{E} W\left({ }_{0} \tilde{\mathbf{c}}\right)$ in the ex post approach, while the right-hand side can be seen to be a lower bound for welfare $W_{0}^{a}$ in the ex ante approach. Hence, if the event that the present is worse off than the future and the event that the present is better off than the future both have positive probabilities, then welfare is lower when adopting the ex post approach. Note that the function that aggregates present utility and future welfare is linear under DU, implying that the two approaches are identical in this case. As explained by Fleurbaey (2010), the issue arises exactly when a priority for the worse off is introduced; SDU does so by giving priority to the future when the future is worse off than the present.

We have used the ex post approach for calculating SDU welfare in the empirical analysis. While it remains a topic for future research to determine what axiomatic basis exists for each of these two approaches - and thereby shed more light on which one fits more naturally with SDU - we offer some remarks to justify our choice.

The ex ante approach entails that individuals are subjected to risk and evaluate prospects by expected utility before the risk is resolved, and that social evaluation is based on the expected utilities of the individuals. In addition to more general problems with the ex ante approach (see, e.g., Fleurbaey, 2010, p. 650, for an illustration 
in terms of climate change), there is a fundamental problem with this approach in the case where future generations are subjected to risk: such ex ante individual evaluation is unavailable. Individuals belonging to future generations in a state where climate change does not affect wellbeing have different identities from those in a state where climate change significantly worsens their situation, and there is no expected utility of their wellbeing on which to base an ex ante social evaluation. In short, in different uncertain states, individuals belonging to future generations must be treated as different individuals. ${ }^{4}$

An ex post evaluation based on SDU when individuals in different states are treated as different individuals must take into account the probability that present utility might exceed future welfare by not assigning utility weight to present utility in such states. This is exactly what we do in the empirical analysis.

In the empirical analysis we also make the assumption that the utility function $U$ not only expresses aversion to fluctuation, but also aversion to risk. It is of interest to separate fluctuation aversion from risk aversion, but this is outside the scope of the present paper. In any case, the identity between fluctuation aversion and risk aversion has been standard in the empirical literature on climate-policy evaluation, so our results will be easier to compare to previous studies in this way.

Adopting the ex post approach comes at a cost: it makes policy evaluation based on SDU time-inconsistent. ${ }^{5}$ A simple example illustrates this issue. Consider two policies. If policy $\mathrm{A}$ is chosen, then consequences are deterministic and consumption is kept constant at a medium level: $c_{m}$, with $U\left(c_{m}\right)=1$. If policy $\mathrm{B}$ is chosen, then consumption is for sure equal to $c_{m}$ in periods 0,1 and 2 . However, the consequences from period 3 onwards are stochastic. With probability 0.5 , consumption thereafter will be high: $c_{h}$, with $U\left(c_{h}\right)=5$. With remaining probability 0.5 , consumption thereafter will be low: $c_{\ell}$, with $U\left(c_{\ell}\right)=0$. Let the utility discount factor, $\delta$, equal 0.5 .

The welfare of policy A equals 1, independently of when it is evaluated. The welfare of policy $\mathrm{B}$ is the average of 5 in period 3, 3 in period 2, 2 in period 1 and 1.5 in period 0 , on the one hand if the good outcome is realised, and 0 , independently of the time of evaluation, on the other hand if the bad outcome is realised. Thus,

\footnotetext{
${ }^{4}$ This statement holds in a non-overlapping generations model. With the ten year periods used in the empirical analysis of this paper, people are subjected to risk within their own lifetimes. We abstract from this since the intergenerational consequences seem more important. This is analogous to abstracting from the self-interested discounting that people do within their own lifetimes.

${ }^{5}$ In principle, also the ex ante approach may lead to time-inconsistency; see Hammond (1989).
} 
the welfare of policy B equals 2.5 in period 3, 1.5 in period 2, 1 in period 1, and 0.75 in period 0 . Hence, in period 0 policy evaluation favours policy A. However, if the choice is delayed until period 2 , then the ranking is reversed.

The reason for this reversal is that the excess utility of $c_{m}$ as compared to $c_{\ell}$ in periods 0,1 , and 2 is "wasted" if the bad outcome is realised. This waste is reduced as the date of evaluation is moved forward, thereby making the bad outcome less disastrous and policy B relatively more attractive. Time-consistency can be restored by taking into account the utility wasted by earlier generations. However, doing so will instead lead to a possibly unattractive dependence on the "utilities of the dead" (cf. Blackorby et al., 1995; Bommier and Zuber, 2008).

\section{Risk analysis with DICE}

In order to examine empirically the differences between climate policy evaluation under SDU and DU, we employ the DICE integrated assessment model of the joint climate-economy system, built by William Nordhaus (we adapt the 2007 version of the model, described in Nordhaus, 2008). In brief, DICE couples a neoclassical model of economic growth to a simple model of the climate system. ${ }^{6}$ Output of a composite good is produced using aggregate capital and labour inputs, augmented by exogenous total factor productivity (TFP) in a Cobb-Douglas production function. However, industrial production is also associated with the emission of carbon dioxide, which is an input to the simple climate model, ${ }^{7}$ resulting in radiative forcing of the atmosphere and an increase in global mean temperature. The climate model couples back to the economy by means of a so-called 'damage function', which is a reduced-form polynomial equation associating a change in temperature with a loss in utility, expressed in terms of equivalent output. The damage function in DICE implicitly takes account of the economy and society's capacity to adapt to climate change, which reduces the amount of output lost for a given increase in global mean temperature, so that the representative agent is left to choose how much to invest in abating $\mathrm{CO}_{2}$ emissions from production. The model is globally aggregated and is

\footnotetext{
${ }^{6}$ IPCC (Houghton et al., 1997) coined the term 'simple climate model' to denote models, which specify the atmosphere, surface and deep oceans as one-dimensional, uniformly mixed boxes, which exchange heat and/or $\mathrm{CO}_{2}$ with each other. By contrast, atmosphere-ocean general circulation models (AOGCMs), the most complex type of climate model, divide the atmosphere and ocean into a detailed three-dimensional grid, with many longitudinal, latitudinal and vertical points.

${ }^{7}$ Alongside exogenous emissions of carbon dioxide from land use.
} 
resolved in decadal time steps from 2005 up to 2395.

DICE is described in full in Nordhaus (2008), and for the sake of brevity we focus our exposition here on those parts of the model we have modified. ${ }^{8}$ Since uncertainty is central to climate policy, we select a subset of eight of the most important parameters in DICE, and specify each as random. Table 1 lists these parameters and the form and parameterisation of their probability distributions. In selecting these eight parameters, we have followed the lead of Nordhaus' (2008) own risk analysis. However, in the case of two parameters, we have chosen an alternative specification. They describe the climate sensitivity and the curvature of the damage function, and we devote special attention to them below. We use a standard, iso-elastic utility function, and calculate classical utilitarian social welfare recursively, using eqs. (6) and (7) for DU and SDU respectively. The probability distributions of the random parameters are sampled using a Latin Hypercube, and social welfare is computed separately for each draw and then weighted by its (identical) probability as described above.

The first four parameters in Table 1 play a role in determining $\mathrm{CO}_{2}$ emissions. Of these four parameters, Kelly and Kolstad (2001) showed that growth in TFP and in population are particularly important. The reason is that, in integrated assessment models such as DICE, growth in $\mathrm{CO}_{2}$ emissions is proportional to growth in global economic output, which in turn is determined in significant measure by productivity growth and by the stock of labour. In addition, where a classical utilitarian SWF is applied, the larger (smaller) is the population when the impacts of climate change occur, the higher (lower) is the social valuation of climate damage. However, while $\mathrm{CO}_{2}$ emissions are proportional to output, the proportion is usually assumed to decrease over time due to changes in economic structure away from $\mathrm{CO}_{2}$-intensive production activities, and to increases in the efficiency of output with respect to $\mathrm{CO}_{2}$ emissions in a given activity. In DICE, this is achieved by virtue of a variable representing the ratio of emissions/output, which decreases over time as a function of a rate-of-decarbonisation parameter. A further check on industrial $\mathrm{CO}_{2}$ emissions is provided in the long run by the finite total remaining stock of fossil fuels, which is also treated here as an uncertain parameter.

The fifth uncertain parameter in Table 1 is the price of a so-called 'backstop' technology, which in the context of climate-change mitigation is the price of a technology that is capable of completely nullifying $\mathrm{CO}_{2}$ emissions. In DICE, the backstop is

\footnotetext{
${ }^{8}$ We adapt the MS Excel version of the model, which is convenient for running risk analysis using the @Risk and Riskoptimizer plug-ins.
} 
Table 1. Uncertain parameters for simulation of modified DICE-2007.

\begin{tabular}{|c|c|c|c|c|c|}
\hline Parameter & Units & $\begin{array}{l}\text { Functional } \\
\text { form }\end{array}$ & Mean & $\begin{array}{l}\text { Standard } \\
\text { deviation }\end{array}$ & Source \\
\hline $\begin{array}{l}\text { Initial growth } \\
\text { rate of TFP }\end{array}$ & $\begin{array}{l}\text { Per } \\
\text { year }\end{array}$ & Normal & 0.0092 & 0.004 & $\begin{array}{c}\text { Nordhaus } \\
\text { (2008) }\end{array}$ \\
\hline $\begin{array}{l}\text { Asymptotic } \\
\text { global population }\end{array}$ & Millions & Normal & 8600 & 1892 & $\begin{array}{c}\text { Nordhaus } \\
(2008)\end{array}$ \\
\hline $\begin{array}{l}\text { Rate of } \\
\text { decarbonisation }\end{array}$ & $\begin{array}{l}\text { Per } \\
\text { year }\end{array}$ & Normal & -0.007 & 0.002 & $\begin{array}{c}\text { Nordhaus } \\
(2008)\end{array}$ \\
\hline $\begin{array}{l}\text { Total resources } \\
\text { of fossil fuels }\end{array}$ & $\begin{array}{l}\text { Billion tons } \\
\text { of carbon }\end{array}$ & Normal & 6000 & 1200 & $\begin{array}{c}\text { Nordhaus } \\
(2008)\end{array}$ \\
\hline $\begin{array}{l}\text { Price of back- } \\
\text { stop technology }\end{array}$ & $\begin{array}{l}\text { US\$ per ton of } \\
\text { carbon replaced }\end{array}$ & Normal & 1170 & 468 & $\begin{array}{c}\text { Nordhaus } \\
(2008)\end{array}$ \\
\hline $\begin{array}{l}\text { Transfer coefficient } \\
\text { in carbon cycle }\end{array}$ & $\begin{array}{c}\text { Per } \\
\text { decade }\end{array}$ & Normal & 0.189 & 0.017 & $\begin{array}{c}\text { Nordhaus } \\
(2008)\end{array}$ \\
\hline $\begin{array}{l}\text { Climate } \\
\text { sensitivity }\end{array}$ & $\begin{array}{l}{ }^{\circ} \mathrm{C} \text { per doubling of } \\
\text { atmospheric } \mathrm{CO}_{2}\end{array}$ & $\begin{array}{c}\text { Log- } \\
\text { normal }\end{array}$ & $1.099^{*}$ & $0.3912^{*}$ & $\begin{array}{c}\text { Weitzman } \\
(2009)\end{array}$ \\
\hline $\begin{array}{l}\text { Damage function } \\
\text { coefficient } \alpha_{3}\end{array}$ & $\begin{array}{l}\text { Fraction of } \\
\text { global output }\end{array}$ & Normal & 0.082 & 0.028 & $\begin{array}{c}\text { Own } \\
\text { estimate }\end{array}$ \\
\hline
\end{tabular}

*In natural logarithm space.

deployed if the control rate on $\mathrm{CO}_{2}$ emissions reaches $100 \%$, so it is conceptually the marginal cost of the last unit of emissions abatement. Such a technology could most plausibly be a zero-emissions energy technology such as solar or geothermal power. ${ }^{9}$ The backstop price starts very high (mean $=\mathrm{US} \$ 1170 / \mathrm{tC})$, but declines over time. Hence it becomes an important determinant of the cost of abatement in the long run.

The sixth and seventh parameters in Table 1 capture important uncertainties in climate science. At a very high level of abstraction, one can distinguish between (i) uncertainties in climate modelling that derive from the cycling of carbon between its various 'sinks' (the atmosphere, the hydrosphere, the biosphere and the lithosphere), which therefore render forecasts of the atmospheric stock of $\mathrm{CO}_{2}$ for a given pulse of

\footnotetext{
${ }^{9}$ It could also be a geo-engineering technology such as artificial trees to sequester atmospheric $\mathrm{CO}_{2}$, except that DICE has exogenous emissions of $\mathrm{CO}_{2}$ from land use.
} 
emissions uncertain, and (ii) uncertainties in the relationship between a rising stock of atmospheric $\mathrm{CO}_{2}$ and temperature. In DICE, the carbon cycle is represented by a system of equations, each containing several parameters. Here, uncertainty about the carbon cycle is captured in a tractable way by focussing on a parameter that determines the proportion of $\mathrm{CO}_{2}$ in the atmosphere in a particular time period, which dissolves into the upper ocean in the next period.

\subsection{Climate sensitivity}

Uncertainty about the relationship between atmospheric $\mathrm{CO}_{2}$ and temperature is captured by a random climate-sensitivity parameter. The climate sensitivity is the increase in global mean temperature, in equilibrium, that results from a doubling in the atmospheric stock of $\mathrm{CO}_{2}$. In simple climate models, it is critical in determining how fast and how far the planet is forecast to warm in response to emissions. The IPCC's Fourth Assessment Report compiled a number of recent estimates of the climate sensitivity (IPCC, 2007). It concluded that the best estimate of the climate sensitivity is $3^{\circ} \mathrm{C}$, that there is a greater than $66 \%$ chance of it falling in the range $2-$ $4.5^{\circ} \mathrm{C}$ (the IPCC's "likely" range), and a less than $10 \%$ chance of it being lower than $1.5^{\circ} \mathrm{C}$ ("very unlikely"). This leaves around a $17 \%$ chance that the climate sensitivity exceeds $4.5^{\circ} \mathrm{C}$, and indeed a critical feature of all 18 probability density functions of the climate sensitivity compiled by IPCC is that they have a positive skew, with a long tail of high estimates. These tails can be attributed to uncertainty about feedbacks (Roe and Baker, 2007), related for example to clouds and water vapour, and about the cooling effect of aerosols.

In Nordhaus' (2008) risk analysis with DICE, the random climate-sensitivity parameter is normally distributed with a mean of $3^{\circ} \mathrm{C}$ and a standard deviation of $1.1^{\circ} \mathrm{C}$. Compared with the evidence compiled by IPCC, however, this distribution may significantly underestimate the probability of very high values. For example, a value of $6.3^{\circ} \mathrm{C}$, which is three standard deviations from the mean of Nordhaus' normal distribution, is assigned a probability of only around $0.1 \%$, whereas several of the pdfs in IPCC (2007) put the corresponding probability at 5-10\%. Similarly, in his review of the evidence, Weitzman (2009) considers that there is a $1 \%$ chance of the climate sensitivity exceeding $10^{\circ} \mathrm{C}$. According to the above normal distribution, this is less likely than a 'six sigma' event, so it has a probability of less than $10^{-7 \%}$. Therefore we specify the random climate-sensitivity parameter as lognormally distributed. With the parameterisation in Table 1 , it can easily be verified that a value of at least 
$6.3^{\circ} \mathrm{C}$, for example, is associated with a $3 \%$ probability.

\subsection{The damage function}

The final parameter in Table 1 is one element of the damage function linking temperature and utility-equivalent losses in output. In recent years, there has been increasing focus in climate-change economics on this critical function (e.g. Weitzman, 2010a), which is unsurprising when one considers that, without the damage function, the accumulation of atmospheric $\mathrm{CO}_{2}$ has no consequence for social welfare. In many past studies, including those with DICE, the approach has been to specify losses in output as a quadratic function of global mean temperature:

$$
\Omega(T)=\frac{1}{1+\alpha_{1} T_{t}+\alpha_{2} T_{t}^{2}},
$$

where $\Omega$, to keep our nomenclature consistent with Nordhaus (2008), is the proportion of output lost at time $t, T$ is the increase in global mean temperature over the pre-industrial level, and $\alpha_{1}$ and $\alpha_{2}$ are coefficients.

The coefficients $\alpha_{1}$ and $\alpha_{2}$ are calibrated on the large literature devoted to estimating the cost of climate change in particular sectors of the economy, such as agriculture, energy, and health (summarised in Parry et al., 2007). This literature provides estimates of varying reliability and validity, but it can generally be concluded that the loss in utility for warming of up to about $3^{\circ} \mathrm{C}$ is relatively well constrained, and is equivalent to a few percent of output. Unfortunately, what the impacts of climate change will be for larger amounts of global warming remains largely in the realm of guesswork (Weitzman, 2009), due to possible non-linearities in the biophysical and socio-economic response to changes in climate variables, as well as possible singularities in the climate system itself (e.g. a collapse in the Antarctic ice sheet, or a shutdown in the ocean circulation), all of which are very poorly understood at present. This points the spotlight at the functional form for damages.

There has never been any stronger justification for the assumption of quadratic damages than the general supposition of a non-linear relationship, added to the fact that quadratic functions are of a familiar form to economists, with a tractable linear first derivative (i.e. the marginal benefit function of emissions reductions). However, when extrapolated to large temperature levels, the implications of a quadratic function have recently been cast in doubt. Both Ackerman et al. (2010) and Weitzman (2010b) have shown that, with Nordhaus' (2008) calibration of eq. (8), $5^{\circ} \mathrm{C}$ warming results in a loss of utility equivalent to just $6 \%$ of output, despite such warming being 
equivalent to the difference between the present global mean temperature and the temperature at the peak of the last ice age, while it takes around $18^{\circ} \mathrm{C}$ of warming for losses in utility to exceed the equivalent of $50 \%$ of output.

There are various ways to remedy what is increasingly regarded as an implausible forecast (Ackerman et al., 2010; Stern Review, 2007; Weitzman, 2009). Following (8), utility losses can be ramped up by increasing the coefficients $\alpha_{1}$ and $\alpha_{2}$, but only at the expense of unrealistically large losses in utility for the initial $3^{\circ} \mathrm{C}$ warming. Conceptually, much follows from the specification of the utility function. Working with a standard utility function whose sole argument is consumption of the composite good, we can introduce a higher-order term into the damage function to capture greater non-linearity, as Weitzman (2010b) does. ${ }^{10}$ We specify the following function:

$$
\Omega(T)=\frac{1}{1+\alpha_{1} T_{t}+\alpha_{2} T_{t}^{2}+\tilde{\alpha}_{3} T_{t}^{7}},
$$

where $\tilde{\alpha}_{3}$ is a normally distributed random coefficient with mean and standard deviation reported in Table 1 . The remaining coefficients $\alpha_{1}$ and $\alpha_{2}$ are as in Nordhaus (2008). If $\tilde{\alpha}_{3}$ takes its mean value, $5^{\circ} \mathrm{C}$ warming results in a loss of utility equivalent to around $7 \%$ of output, while $50 \%$ of output is not lost until the global mean temperature is roughly $11^{\circ} \mathrm{C}$ above the pre-industrial level. Thus the mean value of function (9) remains fairly conservative at high temperatures. However, when $\tilde{\alpha}_{3}$ is three standard deviations larger than the mean, $5^{\circ} \mathrm{C}$ warming triggers an output loss of around $25 \%$ of output, and $50 \%$ of output is lost when warming reaches just $6^{\circ} \mathrm{C}$. This is very close to the specification of Weitzman (2010b). Conversely, at three standard deviations below the mean, $\tilde{\alpha}_{3}$ is small enough that function (9) virtually collapses to function (8), so our risk analysis on the damage function can be said to span the approaches taken by Nordhaus on the one hand and Weitzman on the other.

\section{Results}

As reported in Section 2, a necessary, but insufficient, condition for SDU welfare to be below DU welfare is that there exists some period $t \geq 0$ such that $c_{t}>c_{t+1}$. This period $t$ has to be smaller than the model's terminal period $T$, as we impose constant consumption beyond $T$. Satisfying this condition will in general depend on

\footnotetext{
${ }^{10}$ The alternative is to specify utility as a function not only of consumption but also of environmental quality directly, for example indexed by global mean warming.
} 
severe climate-change damage, since the DICE model, in line with other integrated assessment models, predicts strong growth in production in the absence of such damage. For example, when all the coefficients $\alpha_{i}$ of the damage function are set to zero, so that damages are 'switched off', global mean consumption per capita in DICE is forecast to grow in real terms from US\$6,667 in 2005, the base year, to US\$26,159 in 2105, and onwards to over US\$80,000 in 2205. ${ }^{11}$ Hence the probability that $c_{t}>c_{t+1}$ for $0 \leq t<T$ may be low, but as long as it is not zero, SDU may lead to a different evaluation of policies to cut $\mathrm{CO}_{2}$ emissions than will DU. Therefore we begin our analysis of the modelling results by investigating the probability that percapita consumption is falling at some point over the modelling horizon, conditional on the schedule of emissions cuts pursued.

To begin with, we examine three such climate-change policies. They are, first, 'business as usual', second, a schedule of emissions cuts to limit the atmospheric concentration of $\mathrm{CO}_{2}$ to twice its pre-industrial level (560 parts per million, hereafter referred to as the $2 \mathrm{CO}_{2}$ policy), and, third, a more aggressive schedule of cuts to limit the concentration of $\mathrm{CO}_{2}$ to only one-and-a-half times its pre-industrial level (420ppm, hereafter referred to as the $1.5 \mathrm{CO}_{2}$ policy). The latter two schedules, the abatement schedules, have both been prominent in recent international negotiations about climate policy. Figure 1 presents estimates of the probability that, for each of these three policies, $c_{t}>c_{t+1}$ with respect to any two successive time periods between 2005 and 2205. For this analysis, and the welfare evaluation of the policies in Section 4.1 below, the Latin Hypercube sample comprises 1000 draws.

\section{[FIGURE 1 ABOUT HERE]}

Figure 1 shows that the probability of falling consumption per capita is positive, but very small, under all three policies. Indeed, for the coming century, the probability is virtually the same across the three policies, despite the very different emissions control rate under business as usual compared with those under the two abatement policies. This can be attributed to two causes. First, climate damage can be so large as to drive consumption growth negative, irrespective of the emissions controls put in place. ${ }^{12}$ Second, our assumption of a normally distributed initial growth rate of TFP

\footnotetext{
${ }^{11}$ Using Nordhaus' (2008) standard values for DICE's variables and parameters.

${ }^{12}$ In fact, Figure 1 shows that aggressive initial emissions abatement along the $1.5 \mathrm{CO}_{2}$ policy path actually makes matters worse for a time, as the high initial cost of abatement drives consumption growth negative earlier than under the other two policies in one of the 1000 draws.
} 
makes it possible that TFP falls and takes consumption per capita with it. However, what Figure 1 clearly shows is the pay-off to abatement in the $22^{\text {nd }}$ century, when the probability of falling consumption increases significantly under business as usual, while remaining broadly steady under the $2 \mathrm{CO}_{2}$ and $1.5 \mathrm{CO}_{2}$ abatement policies.

\subsection{Welfare evaluation of emissions cuts}

Table 2 goes on to examine what these underlying estimates of consumption per capita mean for SDU and DU welfare.

Before we explain the results, a few words are in order about our measure of welfare changes. In computing social welfare according to SDU and DU, we obtain the value of the two abatement policies compared with business as usual in terms of social welfare, measured in utils. We need to express the change in social welfare due to abatement in consumption-equivalent terms, in order to quantify willingness to pay. However, matters are complicated by the very large changes in social welfare we must contemplate as a result of the risk analysis (e.g. in a future contingency where climate damage is severe under business as usual, but can largely be avoided by abatement). We cannot simply normalise the change in social welfare using the (inverse of the) marginal social welfare of a unit of consumption, ${ }^{13}$ because the welfare change may not be marginal, so that the first-order approximation of the utility function may be poor. Therefore we turn to the stationary equivalent consumption, a concept which, following Weitzman (1976), is a standard way of representing social welfare in dynamic settings and which we have already discussed in Section $2{ }^{14}$

Table 2 displays our estimates of the stationary equivalent consumption of the $2 \mathrm{CO}_{2}$ and $1.5 \mathrm{CO}_{2}$ abatement policies, compared with business as usual, according to both SDU and DU. We report the mean estimate, i.e. the expected change in the stationary equivalent, and also indicate the nature of the underlying distribution of the change in the stationary equivalent by reporting both the $5^{\text {th }}$ and $95^{\text {th }}$ percentiles.

\footnotetext{
${ }^{13}$ Whereby $\frac{1}{U^{\prime}} \Delta W$ is our welfare change measure in consumption-equivalent terms, where $\Delta W$ is the change in social welfare according to either SDU or DU between one of the two abatement policies on the one hand and business as usual on the other.

${ }^{14}$ We could instead have applied the balanced growth equivalent (BGE) introduced by Mirrlees and Stern (1972). The BGE of a given amount of social welfare is the initial level of consumption per capita, which, if it grows at a constant annual rate over all time, yields the same amount of social welfare. However, as Anthoff and Tol (2009) show, the stationary equivalent consumption gives the same result as the BGE (independently of the choice of growth rate), provided the utility function exhibits constant fluctuation/risk aversion.
} 
Table 2. Change in expected stationary equivalent of $2 \mathrm{CO}_{2}$ and $1.5 \mathrm{CO}_{2}$ policies compared with business as usual, according to SDU and DU.

\begin{tabular}{lcccccc}
\hline \hline $\begin{array}{l}\text { Abatement } \\
\text { policy }\end{array}$ & $5 \%$ & Mean & $95 \%$ & $5 \%$ & Mean & $95 \%$ \\
\hline $2 \mathrm{CO}_{2}$ & -0.13 & 4.70 & 0.72 & -0.14 & 0.20 & 0.67 \\
$1.5 \mathrm{CO}_{2}$ & -1.69 & 3.83 & 0.51 & -1.70 & -0.67 & 0.41 \\
\hline
\end{tabular}

The utility discount rate $\rho$ in these calculations is 0.02 , thus the per-period (i.e. decadal) discount factor is $\sim 0.82$, and the coefficient of fluctuation/risk aversion is set to two. For these (and all subsequent) calculations, we use the full modelling horizon from 2005 to 2395 . The savings rate for this part of the analysis is exogenous (set at 0.22 or $22 \%$ ), enabling us to thoroughly explore parametric uncertainty by diverting computing resources to a large Latin Hypercube sample (1000 draws), rather than optimal control of savings. ${ }^{15}$ In the next section, however, where we consider optimal emissions control, savings are a choice variable.

The table contains our core result, showing that willingness to pay for emissions abatement is significantly larger under SDU than under DU. For the $2 \mathrm{CO}_{2}$ policy, the expected increase in the stationary equivalent is $4.7 \%$ under SDU, over twentyfold higher than the corresponding estimate of $0.2 \%$ under DU. For the $1.5 \mathrm{CO}_{2}$ policy, the expected increase is $3.83 \%$ under SDU, but $-0.67 \%$ under DU. Intriguingly, this policy reduces social welfare according to DU, but according to SDU it increases it. These results follow directly from the finding, detailed in Figure 1, that consumption is more likely to fall under business as usual than under either of the two abatement policies. SDU places greater value on these policies than DU as a consequence: they are more likely to guarantee sustainability, defined as non-decreasing wellbeing.

What Table 2 also shows is the influence of uncertainty, specifically the small number of random draws in which climate damage is severe. This is evident in comparing the expected change in the stationary equivalent with the $95^{\text {th }}$ percentile change under SDU. For both policies, the expected change is in fact greater than the

\footnotetext{
${ }^{15}$ In our multi-parameter risk analysis, adding a choice variable increases computational demands hugely. Nordhaus claims that the results of DICE simulations with a constant $22 \%$ savings rate are virtually identical to results with endogenous savings, for DU and standard parameter values. Fankhauser and Tol (2005) also show that endogenising the savings rate makes little difference to the economic impact of climate change.
} 
$95^{\text {th }}$ percentile, indicating that a few random draws (less than 5\%) have a change in the stationary equivalent so large as to drive the expectation above the $95^{\text {th }}$ percentile. This is one way of showing that concerns about intergenerational equity and concerns about uncertainty are closely linked in the context of climate change.

Figure 2 explores the sensitivity of the expected change in the stationary equivalent as estimated under both SDU and DU to $\rho$. We examine values for $\rho \in(0,0.05)$ (corresponding to a range for the decadal discount factor of 1-0.62). It is evident that, in line with the distribution of near-term abatement costs and longer-term benefits, the expected change in the stationary equivalent of the two abatement policies is a decreasing function of $\rho$, both under SDU and under DU. Indeed, it falls rapidly as $\rho$ is initially increased from 0 .

[FIGURE 2 ABOUT HERE]

However, what is more interesting is that the expected change in the stationary equivalent under SDU holds up to a greater extent than under DU, so that the difference between the two evaluation principles grows. When $\rho=0$, the two principles yield an identical evaluation. The reason for this can readily be seen by comparing (w.1) and (W.1) in Section 2: when the discount factor approaches unity, the SDU algorithm approaches the DU algorithm. ${ }^{16}$ However, as $\rho$ increases, the two algorithms can yield different results depending on the probability of falling consumption per capita, and Figure 2 bears this out. For both policies, the expected change in the stationary equivalent falls and eventually becomes negative under DU, but remains positive under SDU. As $\rho$ rises, the far-off future matters less and less under DU, and it is in the far-off future that the benefits of abatement accrue. However, under SDU the far-off future can continue to receive significant weight, if at some point in time future discounted utility is below present utility. We know from Figure 1 that this is the case.

\subsection{Optimal policies}

Finally, rather than evaluating exogenous policy settings, it is informative to compare the optimal schedule of emissions abatement under SDU and DU. To do this, we

\footnotetext{
${ }^{16}$ In the limit, as $\rho \rightarrow 0$, or equivalently, $\delta \rightarrow 1$, it follows from (w.1), (w.2), (W.1) and (W.2) that DU and SDU welfare are determined only by the eventual constant part of ${ }_{0} \mathbf{c}$ beyond $T$, where $c_{t}=c_{T}$ for all $t \geq T$. Then both DU and SDU welfare become insensitive to present wellbeing, as $w\left({ }_{0} \mathbf{c}\right)=W\left({ }_{0} \mathbf{c}\right)=U\left(c_{T}\right)$, illustrating a problematic aspect of undiscounted utilitarianism.
} 
set $\rho=0.02$, and follow Nordhaus (2008) in simultaneously solving a schedule of emissions control rates $\left\{\mu_{t}\right\}$ (where for each $t, \mu_{t} \in[0,1]$ ) and a schedule of savings rates $\left\{s_{t}\right\}$ that determines the share of output consumed/invested (where for each $t$, $\left.s_{t} \in[0,1]\right)$, which together maximise the expectation of SDU and DU respectively. Thus the emissions control rate is a number between 0 and 1, which controls the emissions intensity of output, and a control rate of $\mu_{t}$ results in a fraction $1-\mu_{t}$ of output contributing to emissions.

In an integrated assessment model such as DICE, and especially in running risk analysis, solving this optimisation problem is a non-trivial computational challenge. However, we are able to find a solution using a genetic algorithm (Riskoptimizer) and with two modifications to the basic optimisation problem. ${ }^{17}$ In addition, we take a smaller Latin Hypercube Sample of 250 draws. ${ }^{18}$ Figure 3 presents the schedule of optimal emissions abatement corresponding to SDU and DU. It can be seen, intuitively, that emissions abatement is at least as high under SDU as it is under DU in every time period, and is considerably higher in some, specifically in the latter half of this century and in the next (top panel). The bottom panel also brings out the differences between the two sets of optimal controls, but it further shows that, nevertheless, optimal annual emissions are increasing under SDU and DU for at least the next one hundred years (albeit much less than under business as usual, given the control rates). This is explained by our choice of $\rho=0.02$, which favours less aggressive strategies of emissions control, all else equal. Setting $\rho$ closer to zero would see the flow of emissions peaking earlier, under DU and especially under SDU.

\section{[FIGURE 3 ABOUT HERE]}

\footnotetext{
${ }^{17}$ First, we only solve $\mu_{t}$ from 2005 to 2245 inclusive, rather than all the way out to 2395 . This considerably reduces the scope of the optimisation problem, in return for making little difference to the results, since, in the standard version of DICE, $\mu_{t}=1, t>2245$ (i.e. abatement yields high benefits relative to costs in the far-off future). Our own results also show that $\mu_{t} \rightarrow 1$ as $t \rightarrow 2245$. Second, we guide the optimisation by imposing the soft constraint that $\mu_{t}$ is nondecreasing everywhere (via an exponential penalty function when $\mu_{t}$ decreases between any two time periods). Otherwise, the algorithm struggled to find a path towards the global maximum. As a soft constraint, the penalty does not enter the welfare evaluation. We were able to verify that the algorithm's best solution satisfied the property of non-decreasingness in $\mu_{t}$, and that no solution was found which returned higher SDU/DU, where $\mu_{t}$ was decreasing at any point.

${ }^{18}$ In order to ensure comparability with the results of Section 4.1, the smaller sample is calibrated on the sample statistics of the larger sample.
} 


\section{Concluding remarks}

In this paper we have introduced sustainable discounted utilitarianism (SDU) as an alternative criterion to discounted utilitarianism (DU) for the evaluation of climateabatement policies and we have conducted a risk analysis with the DICE integrated assessment model in order to find out how much the switch matters empirically. To set the stage for this application, we first extended the concept of SDU to variable population and uncertainty (specifically risk). On the back of recent controversies, we also adjusted the climate sensitivity and damage function used in the standard DICE model, as part of our wider risk analysis. The result is that, with our alternative specifications, there is a non-negligible probability that some generation is better off than its descendants due to the impacts of climate change.

In expectations and at an aggregate level, integrated assessment models like DICE assume that the future will be much better off than the present, due largely to the assumption of positive growth in total factor productivity. In our empirical analysis we have exploited the possibility that in contingencies where the climate sensitivity is large (so that the increase in atmospheric $\mathrm{CO}_{2}$ leads to a large rise in temperature) and temperature rise leads to large damages, development of wellbeing may not be monotonically increasing. When such circumstances are assigned positive probability, SDU more than DU promotes present action against climate change, as our analysis has shown. Hence, moving from DU to SDU matters empirically. Furthermore, this result is robust in the sense that the difference between DU and SDU remains substantial even if a high utility discount rate is applied (we looked at rates up to $5 \%$ per annum).

This last observation is particularly significant. In the introduction, we found ourselves agreeing with the arguments of Arrow, Dasgupta, Rawls and others that the use in climate-policy evaluation of undiscounted utilitarianism, or similarly the use of DU with a near-zero utility discount rate, leads to unappealing transfers of wealth from the present to the future, when applied consistently across the wider set of investment opportunities. Our analysis shows that concern for the wellbeing of future generations might be better taken into account using SDU with a positive utility discount rate substantially away from zero. What precisely that rate should be, when used alongside SDU, ought to be the focus of a renewed discussion, which is beyond the scope of this paper. In any case, we have shown that, within a relatively broad range, tough emissions abatement schedules will continue to increase social 
welfare.

At a spatially disaggregated level, climate change may lead to reduced wellbeing (even when compared to present wellbeing) for certain groups, but not for others. Provided that large-scale compensation schemes will not be undertaken, this applies in particular to those living in geographical areas where climate change is likely to be especially severe, and/or where vulnerability is particularly high. One example is likely to be marginal agricultural regions in Africa; another may be low-lying coastal communities in South and Southeast Asia. At such a disaggregated level, it will matter much more to apply SDU instead of DU, as SDU in effect does not discount the utility loss due to climate change for those groups that are so severely affected.

Therefore, it will be of great interest to apply the SDU criterion (or a similar criterion - extended rank-discounted utilitarianism - proposed by Zuber and Asheim, 2011) for evaluating climate change in models where effects are disaggregated on groups, and compare DU to alternative criteria in such a setting. We will turn to this in future work. However, even the present analysis is strongly indicative of the importance of broadening the basis of climate-policy evaluation from DU to SDU and beyond.

Finally, we should comment on the prospect that SDU might actually be applied in policy-making. SDU is the outcome of an explicitly ethical approach to policy evaluation (and within that, an axiomatic approach). As such, one is challenged to adopt an impartial perspective on questions of intergenerational distribution. In reality of course, the present generation - seen as one of a series of non-overlapping generations - enjoys the autonomy to make its own decisions, and the incentive to behave self-interestedly is strong. From a positive point of view, undiscounted utilitarianism can be criticised for this reason: there is plenty of evidence to show that the utility of future generations is discounted at some substantially positive rate, despite ethical objections. However, our conviction is that the case for DU depends in large part on the assumption that the future will be better off than the present for certain, such that if the present generation believed its decisions could leave the future worse off than it, it could be persuaded to revise those decisions. Hence we do believe that the criterion of SDU might capture important aspects of the present generation's evaluation of climate policies, and other policies where the sustainability of wellbeing is under threat. 


\section{References}

Ackerman, F., E.A. Stanton and R. Bueno (2010), Fat tails, exponents, extreme uncertainty: simulating catastrophe in DICE. Ecological Economics 69(8), 16571665.

Anthoff, D. and R.S.J. Tol (2009), The impact of climate change on the balancedgrowth-equivalent: an application of FUND. Environmental and Resource Economics 43, 351-367.

Arrow, K.J. (1999), Discounting, morality, and gaming. In Discounting and Intergenerational Equity. P.R. Portney and J.P. Weyant. Resources for the Future, Washington, DC.

Asheim, G.B. (2010), Intergenerational equity. Annual Review of Economics 2, 197222.

Asheim, G.B. and T. Mitra (2010), Sustainability and discounted utilitarianism in models of economic growth. Mathematical Social Science 59, 148-169.

Asheim, G.B., T. Mitra and B. Tungodden (2012), Sustainable recursive social welfare functions. Economic Theory 49, 267-292.

Blackorby, C., W. Bossert and D. Donaldson (1995), Intertemporal population ethics: critical-level utilitarian principles. Econometrica 63, 1303-1320.

Blackorby, C., W. Bossert and D. Donaldson (2005), Population Issues in Social Choice Theory, Welfare Economics, and Ethics. Cambridge University Press, Cambridge, UK.

Bommier, A. and S. Zuber (2008), Can preferences for catastrophe avoidance reconcile social discounting with intergenerational equity? Social Choice and Welfare 31, 415-434.

Chichilnisky, G. (1996), An axiomatic approach to sustainable development. Social Choice and Welfare 13, 231-257.

Cline, W.R. (1992), The Economics of Global Warming. Institute for International Economics, Washington, DC. 
Dasgupta, P.S. (2001), Human wellbeing and the Natural Environment. Oxford University Press, Oxford, UK.

Dasgupta, P.S. (2007). Commentary: the Stern Review's economics of climate change. National Institute Economic Review 199, 4-7.

Diamond, P. (1965). The evaluation of infinite utility streams. Econometrica 33, $170-177$.

Fankhauser, S. and R.S.J. Tol (2005). On climate change and economic growth. Resource and Energy Economics 27, 1-17.

Fleurbaey, M. (2010). Assessing risky social situations. Journal of Political Economy 118, 649-680.

Hammond, P.J. (1989). Consistent plans, consequentialism, and expected utility. Econometrica 57, 1445-1449.

Houghton, J.T., L.G. Meira Filho, D.J. Griggs and K. Maskell (eds) (1997), An introduction to simple climate models used in the IPCC Second Assessment Report. IPCC Technical Paper II. IPCC, Geneva.

IPCC (2007), Summary for policymakers. In Climate Change 200\%: The Physical Science Basis. Contribution of Working Group I to the Fourth Assessment Report of the Intergovernmental Panel on Climate Change. S. Solomon, D. Qin, M. Manning, Z. Chen, M. Marquis, K.B. Averyt, M. Tignor and H.L. Miller. Cambridge University Press, Cambridge, UK and New York, NY.

Kelly, D.L. and C. Kolstad (2001), Malthus and climate change: betting on a stable population. Journal of Environmental Economics and Management 41, 135-161.

Meade, J.E. (1955), Trade and Welfare. Oxford University Press, Oxford, UK.

Mirrlees, J.A. (1967), Optimal growth when the technology is changing. Review of Economic Studies (Symposium) 34, 95-124.

Mirrlees, J.A. and N.H. Stern (1972), Fairly good plans. Journal of Economic Theory 4, 268-288.

Nordhaus, W.D. (1991), To slow or not to slow: the economics of the greenhouse effect. Economic Journal 101, 920-937. 
Nordhaus, W.D. (2008), A Question of Balance: Weighing the Options on Global Warming Policies. Yale University Press, New Haven, CT and London.

Parry, M.L., O.F. Canziani, J.P. Palutikof, and co-authors (2007), Technical summary. In Climate Change 200\%: Impacts, Adaptation and Vulnerability. Contribution of Working Group II to the Fourth Assessment Report of the Intergovernmental Panel on Climate Change. M.L. Parry, O.F. Canziani, J.P. Palutikof, P.J. van der Linden and C.E. Hanson. Cambridge University Press, Cambridge, UK, $23-78$.

Pigou, A.C. (1932), The Economics of Welfare. MacMillan, London.

Ramsey, F.P. (1928), A mathematical theory of saving. The Economic Journal 38(152), 543-559.

Rawls, J. (1971), A Theory of Justice. Harvard University Press, Cambridge, MA.

Roe, G.H. and M.B. Baker (2007), Why is climate sensitivity so unpredictable. Science 318, 629-632.

Stern, N. (2007), The Economics of Climate Change: the Stern Review. Cambridge University Press, Cambridge, UK.

Weitzman, M.L. (1976), On the welfare significance of national product in a dynamic economy. Quarterly Journal of Economics 90, pp. 156-162.

Weitzman, M.L. (2009), On modeling and interpreting the economics of catastrophic climate change. Review of Economics and Statistics 91, 1-19.

Weitzman, M.L. (2010a), What is the "damages function" for global warming - and what difference might it make? Climate Change Economics 1, 57-69.

Weitzman, M.L. (2010b), GHG targets as insurance against catastrophic climate damages. Mimeo, Department of Economics, Harvard University.

Zuber, S. and G.B. Asheim (2011), Justifying social discounting: the rankdiscounted utilitarian approach. Journal of Economic Theory, forthcoming (doi:10.1016/j.jet.2011.08.001). 


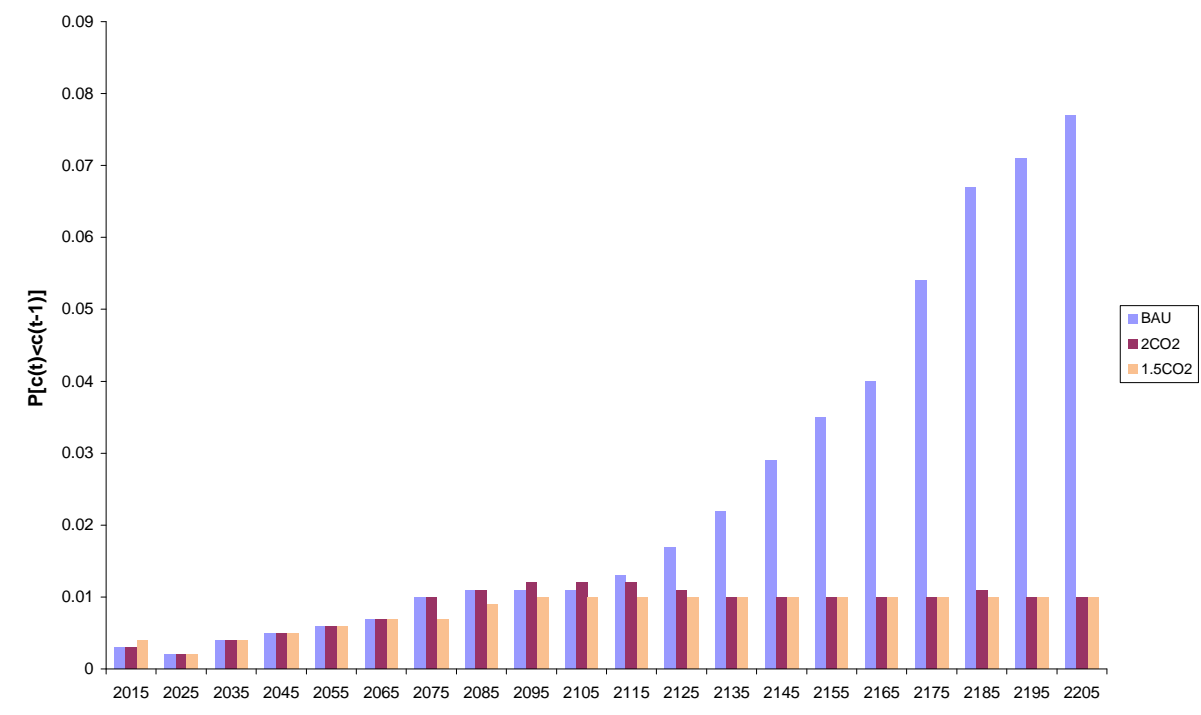

Figure 1: Probability of falling consumption per capita for three emissions abatement policies (business as usual, $2 \mathrm{CO}_{2}$ and $1.5 \mathrm{CO}_{2}$ ). 

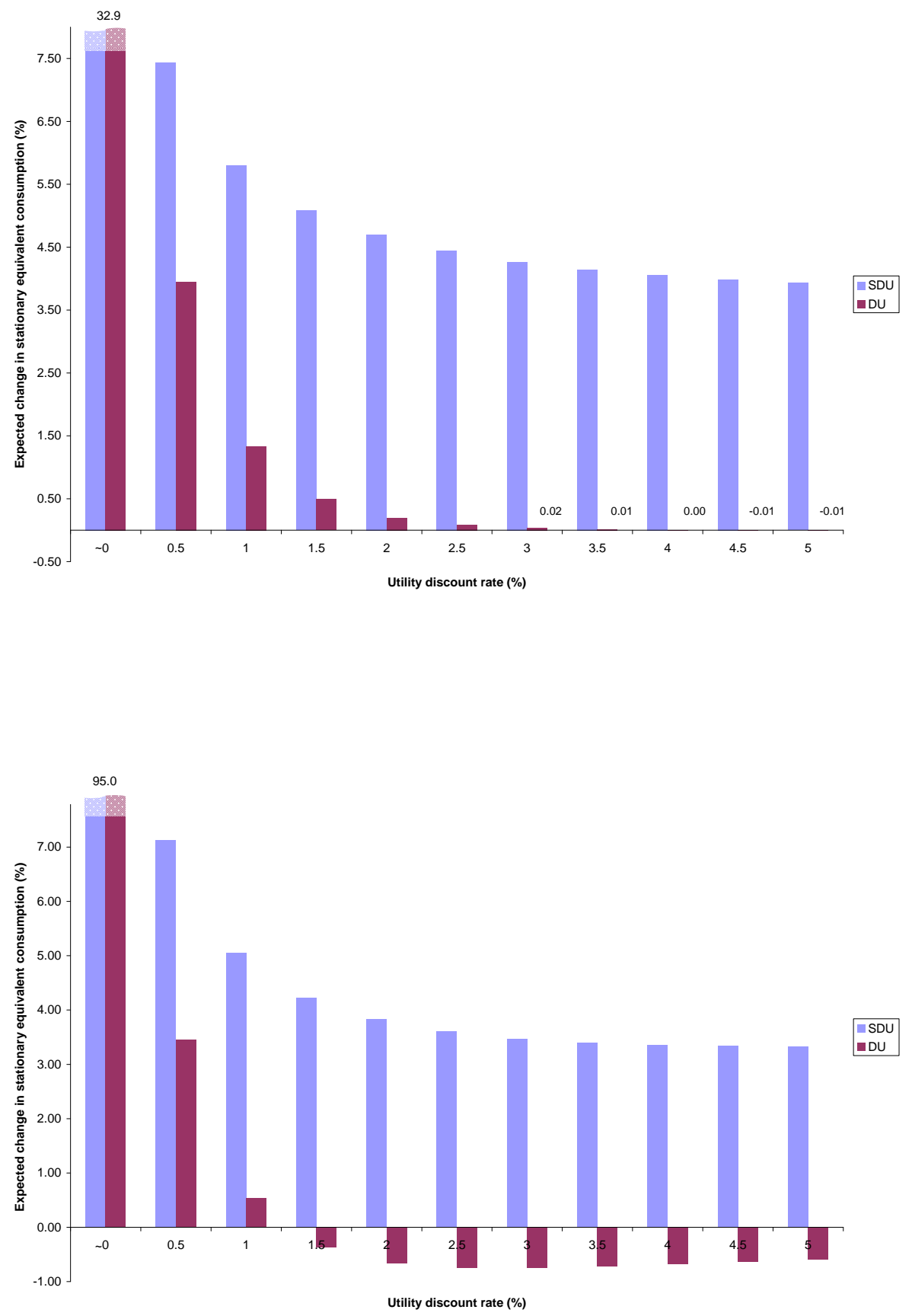

Figure 2: Expected change in stationary equivalent consumption per capita under SDU and DU as a function of the utility discount rate, for the $2 \mathrm{CO}_{2}$ (top) and 1.5 $\mathrm{CO}_{2}$ (bottom) policies. 

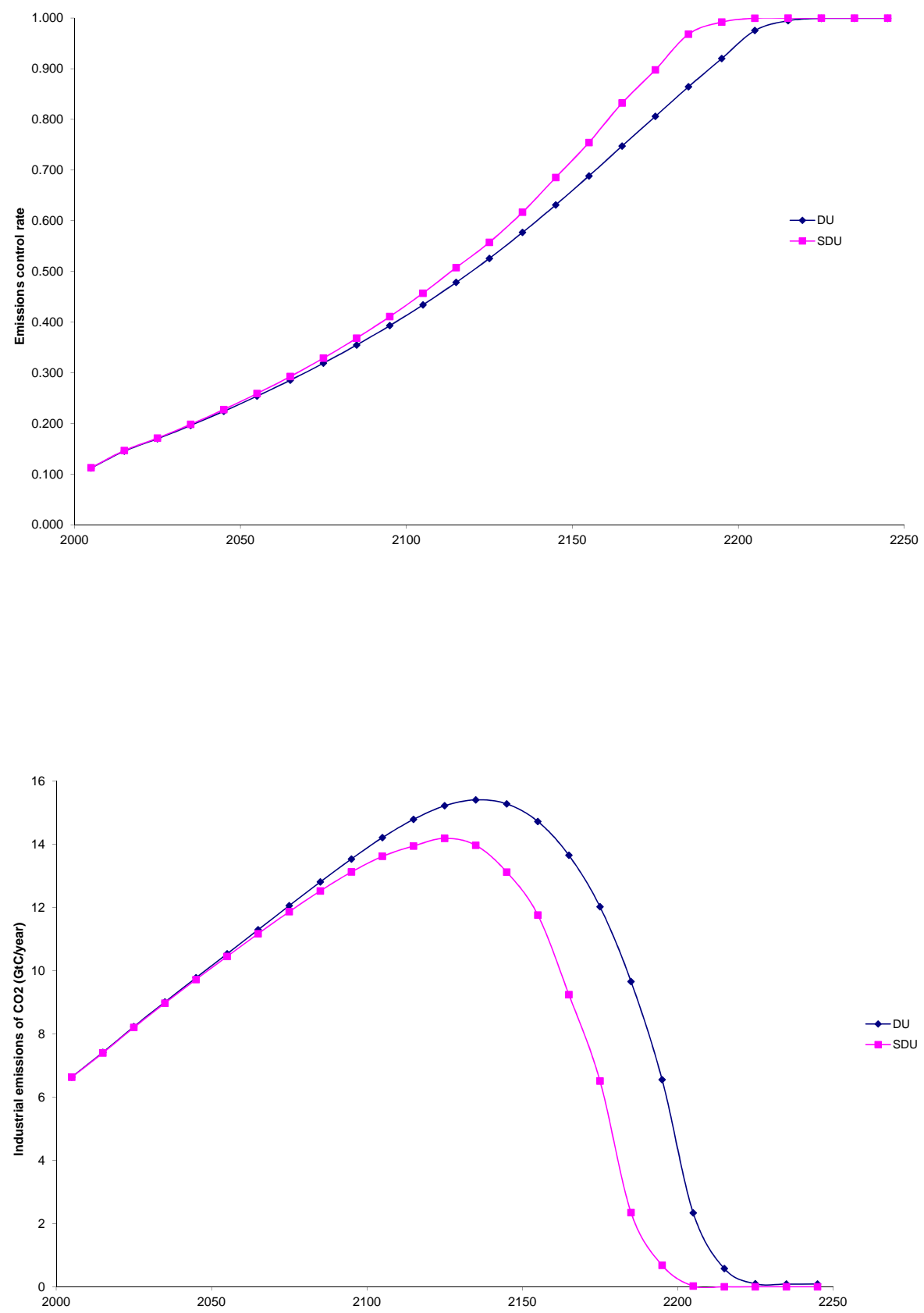

Figure 3: Optimal emissions under SDU and DU in terms of (top) the emissions control rate and (bottom) mean annual industrial $\mathrm{CO}_{2}$ emissions. 